\title{
The Assessment of Natural Rock Asphalt for Thin Surfacing Mixture Design
}

\author{
Ary Setyawan ${ }^{1, *}$, Arif Budiarto ${ }^{1}$, Djumari Djumari ${ }^{1}$ and Salvatore Sukmana ${ }^{2}$ \\ ${ }^{1}$ Roadmate Research Group, Universitas Sebelas Maret, Surakarta 57126, Indonesia \\ ${ }^{2}$ Civil Engineering Department, Universitas Sebelas Maret Surakarta 57126, Indonesia
}

\begin{abstract}
Thin surfacing hot mixed asphalt is one of the alternatives to anticipate the problem of thickness on overlay that are being developed as environment-friendly pavement, but the use of thin surfacing was still not maximum with some weakness. One way to improve the qualities of bitumen is by the use of the modification which has been available in the market. A new materials available in market is retona. Retona (Refined Buton Asphalt) is produced by the extraction of the natural asphalt from Buton island, Indonesia that were developed with a distillation process and extraction. The study has been carried out to define optimum bitumen content and characteristic in hot mix thin surfacing by using retona blend 55 and asphalt penetration $60 / 70$ with the experimental method using the Marshall to define the stability, flow, density, percentage number of pores, Marshal Quotient (MQ). Result of Marshall test thin sufacing hot mix asplhat for optimum bitumen content retona belnd 55 asphalt is 5,87\%, using the same gradations achieved optimum bitumen content of asphalt penetration $60 / 70$ of $5.80 \%$. In each of the asphalt on the conditions of optimum bitumen content obtained difference for characteristic and properties. Stability value retona blend 55 asphalt $525,61 \mathrm{~kg}$, and asphalt penetration of $60 / 70$ is $651,16 \mathrm{~kg}$. The density value of retona blend 55 asphalt $2,06 \%$, and asphalt penetration $60 / 70$ is $2,11 \%$. The percentage of the pores value of retona blend 55 asphalt is $18,45 \%$, and asphalt penetration $60 / 70$ is $15,8 \%$. Flow value retona blend 55 asphalt is $2,11 \mathrm{~mm}$, and asphalt penetration $60 / 70$ is $2,23 \mathrm{~mm}$. Thus asphalt penetration have resistance to traffic loads which is stronger, with a more solid density value, the value of smaller pores and higher flow values than the natural rock asphalt blend retona 55 asphalt.
\end{abstract}

\section{Introduction}

Thin Surfacing Hot Mix Asphalt is one technology that is being developed as a preventive and resurfacing for pavement. Thin Surfacing HMA is a very thin surface layer such as surface dressings and slurries, this thin layer of coating has a thickness from $30 \mathrm{~mm}$ to 40 $\mathrm{mm}[1]$.

Gilbert et al. (2004) states that the main purpose of using Thermal Surfacing Hot Mix Asphalt is for the treatment of road pavement surfaces. The thin layer of HMA can extend

* Corresponding author: arysetyawan@staff.uns.ac.id 
the service life and improve pavement performance such as smoothness, comfort, agitation, noise reduction [2]. The advantages of thin asphalt overlays are long service life, smooth surfaces, able to withstand heavy traffic and large shear stress, high resistance skid, and easy maintenance [3].

Asphaltic characteristics affect the performance of asphalt mixtures. Therefore, asphalt with good quality will produce a pavement mixture with good performance. The use of a thin layer of asphalt mixture is very much required as an alternative or environmentally friendly innovation on the manufacture or maintenance of roads in Indonesia.

Retona (Refined Buton Asphalt) is the product of natural asphalt extraction from Buton Island. An asphalt of 55 blend retona product, from a variety of research blend 55 blend can serve high traffic. Increased stability, fatigue resistance and adhesion due to temperature (fatigue life ratio 4.73-32.62 times greater according to Tu Delft), high adhesion and cohesion strength, water resistance due to retona nitrogen base $5.61( \pm 400 \%)$, Longer service life (at least twice), so the maintenance cost is cheap, easy to use as normal asphalt, Marshal stability up to $30 \%$, dynamic stability rises so that $400 \%$ (average above 3000 trajectory / min), stability Dynamic for heavy loaded and heavy traffic road is minimum 3000 trajectory / $\mathrm{min}$. In this research will be tested the effect of asphalt use for thin layer using asphalt which have been available in Indonesia that is: retona blend 55 asphalt and normal penetration asphalt (Pen.60 / 70).

Several research have been conducted to assess the performance of thin surfacing in application for overlay design as reported by Setyawan et al [4,5]. The application of overlay as the conventional method to maintain the surface quality of pavement need a large number of fresh natural aggregate and bitumen due to the relatively thick layer and consequently the road geometric must be corrected, so that regarded as not environmentally friendly. The alternative solution is Ultra-Thin Surfacing Hot Mix Asphalt (UTSHMA) which has a thickness of $12-15 \mathrm{~mm}$. UTSHMA gradation is designed based on the highest Marshall Quotient value tested by performing Marshall Test of five variations gradation from Standard Specification Construction of Transport Systems. The Optimum Bitumen Content (OBC) obtained by Marshall Test. The bitumen used for this is $60 / 70$ penetration. The several structural tests were performed on the best gradation at OBC consist of Marshall tests, Indirect Tensile Strength (ITS), Unconfined compressive strength (UCS) tests and water permeability test. The UTSHMA mixture with coarse gradation has the greatest Marshall Quotient at 6.35\% OBC accompanied by the higher ITS and UCS properties compare to conventional asphalt concrete. The coefficient permeability of UTSHMA is lower than conventional AC, indicated that UTSHMA is more resistant to water penetration. The research concluded that UTSHMA has compromised the standard specification and has sufficient structural properties compare to conventional AC and can be regarded as structural layer of pavement for overlay and road preservation design [6].

Meanwhile the application of thinner layer such Hot Mixture Asphalt Concrete Overlays (THMACO's) are comprised of a thin layer less than one inch hot mix asphalt concrete layer and a binder material/tack coat. The uses of thin layer are necessary to compromise with the environment issue especially to protect the natural resources and save the energy used during asphalt construction. THMACO's can be used as preventative maintenance on pavement preservation or as a new surface on a pavement construction. This layeris usually regarded as non-structural layer at pavement design. However, this paper presents the structural assessment of this materials and their comparison to the conventional asphalt concrete mixtures. This research was conducted based on indirect tensile strength (ITS), unconfined compressive strength (UCS) and indirect tensile stiffness modulus (ITSM) of thin hot mixture asphalt. The results show that the thin hot mixture asphalt has performed slightly different on the Marshall and structural properties compare to conventional asphalt concrete $[7,8]$ 


\section{Research Method}

\subsection{Aggregate and Gradation}

Aggregates are mineral particles in the form of granules which are one of use in combination with various types ranging from as materials in cement to forming concrete, road layer, filler material, etc. [9]

Mixed gradation planning is based on the National Asphalt Pavement Association (NAPA), North Carolina. The gradation used is presented in Table 1.

Table 1. The Gradation of Thin Surfacing Hot Mixture Asphalt

\begin{tabular}{cccc}
\hline Sieve Sizes $(\mathrm{mm})$ & Specification & Median & $\begin{array}{c}\text { Selected } \\
\text { Gradation }\end{array}$ \\
\hline 3/4" (19 mm) & 100 & & 100 \\
$1 / 2^{\prime \prime}(12,7 \mathrm{~mm})$ & $85-100$ & 92.5 & 92.65 \\
$3 / 8^{\prime \prime}(9,51 \mathrm{~mm})$ & $60-80$ & 70 & 69.3 \\
No.4 $(4,76 \mathrm{~mm})$ & $28-38$ & 33 & 33.62 \\
No.8 $(2,38 \mathrm{~mm})$ & $19-32$ & 25.5 & 25.16 \\
No.50 $(0,297 \mathrm{~mm})$ & $8-13$ & 10 & 10.6 \\
No.200 $(0,074 \mathrm{~mm})$ & $4-7$ & 5.5 & 5.68 \\
\hline
\end{tabular}

\subsection{The optimum bitumen content}

The optimum bitumen content can be determined by Marshall Test or often called Asphalt Institute method. Marshall testing is done based on the estimated asphalt content of $4.5 \%$, $5 \%, 5,5 \%, 6 \%, 6,5 \%$. Before the Marshall test is done, Volumetric test firstly includes measurement of diameter, thickness and weight in the air, then calculated to get density value, $\mathrm{Si}_{\mathrm{x}}$, and porosity. Then just done Marshall testing and got the value of stability, flow, and Marshall Quotient. From these values can be determined the best mixed properties or optimum asphalt content which is then used as the basis in the manufacture of the next test object.

From the Marshall test results obtained parameters in the form of flow value, stability dam Marsahll Quotient, from the data will get the value of the optimum asphalt content of asphalt used.

\section{Results and Discussion}

\subsection{Marshall Stability}

From the results in Table 2, it can be seen that the use of $6 \%$ retona asphalt obtained the highest Marshall stability of $568.38 \mathrm{~kg} ; 573.42 \mathrm{~kg} ; 662.43 \mathrm{~kg}$ with an average of $601.41 \mathrm{~kg}$, while for $60 / 70$ asphalt penetration with $6 \%$ asphalt content obtained the Marshall stability rate of $743.86 \mathrm{~kg} ; 760.59 \mathrm{~kg} ; 684.74 \mathrm{~kg}$; With an average of $729.73 \mathrm{~kg}$ 
Table 2. The Results of Marshall Test

\begin{tabular}{|c|c|c|c|c|c|c|}
\hline \multirow{2}{*}{$\begin{array}{l}\text { Bitumen } \\
\text { contents } \\
(\%)\end{array}$} & \multirow{2}{*}{$\begin{array}{l}\text { Stability } \\
\text { Retona }\end{array}$} & \multirow{2}{*}{$\begin{array}{l}\text { (kg) } \\
\text { 60/70pen }\end{array}$} & \multicolumn{2}{|c|}{ Flow $(\mathrm{mm})$} & \multicolumn{2}{|c|}{$\begin{array}{l}\text { Marshall Quotient } \\
(\mathrm{kg} / \mathrm{mm})\end{array}$} \\
\hline & & & Retona & 60/70pen & Retona & $60 / 70$ pen \\
\hline 5 & 552.76 & 460.69 & 2.3 & 3.25 & 240.33 & 141.75 \\
\hline 5 & 462.64 & 592.98 & 2.1 & 2.1 & 220.31 & 282.37 \\
\hline \multirow[t]{2}{*}{5} & 319.18 & 487.43 & 2.75 & 1.65 & 116.06 & 295.41 \\
\hline & 444.86 & 513.7 & 2.38 & 2.33 & 192.23 & 220.16 \\
\hline 5.5 & 395.53 & 707.66 & 1.9 & 2.1 & 208.17 & 336.98 \\
\hline 5.5 & 514.43 & 672.01 & 2.3 & 2.95 & 223.66 & 227.8 \\
\hline \multirow[t]{2}{*}{5.5} & 429.52 & 490.87 & 2.5 & 1.7 & 171.81 & 288.75 \\
\hline & 446.49 & 623.51 & 2.23 & 2.25 & 201.22 & 277.12 \\
\hline 6 & 568.38 & 743.86 & 2.1 & 2.1 & 270.66 & 354.22 \\
\hline 6 & 573.42 & 760.59 & 1.9 & 2.8 & 301.8 & 271.64 \\
\hline \multirow[t]{2}{*}{6} & 662.43 & 684.74 & 2.3 & 1.65 & 288.01 & 414.99 \\
\hline & 601.41 & 729.73 & 2.1 & 2.18 & 286.82 & 334.23 \\
\hline 6.5 & 413.95 & 480.91 & 2 & 2.2 & 206.97 & 218.59 \\
\hline 6.5 & 452.21 & 427.64 & 1.9 & 2.1 & 238.01 & 203.64 \\
\hline \multirow[t]{2}{*}{6.5} & 427.44 & 446.64 & 1.7 & 2.2 & 251.44 & 203.02 \\
\hline & 431.2 & 451.73 & 1.87 & 2.17 & 232.14 & 208.49 \\
\hline 7 & 361.66 & 334.5 & 1.8 & 2.1 & 200.92 & 159.28 \\
\hline 7 & 431.52 & 454.92 & 1.7 & 2.3 & 253.84 & 197.79 \\
\hline \multirow[t]{2}{*}{7} & 311.15 & 440.05 & 1.9 & 2.1 & 163.76 & 209.55 \\
\hline & 368.11 & 409.82 & 1.8 & 2.17 & 206.17 & 189.15 \\
\hline
\end{tabular}

\subsection{Density}

Density is the ratio between weight and volume (indicating the density of a mixture). The results of the study show that the density decreases with increasing the asphalt content, but will increase after reaching asphalt level $\pm 6 \%$. This is because the mixture has not reached the maximum density at $\pm 6 \%$ asphalt level, or not saturated, so that as the asphalt level increases its density will rise.

The optimum level of retona asphalt content, the value of density 2,06 from the density value still increases at $6 \%, 6,5 \%$ and $7 \%$, it shows that the optimum Retona asphalt content has not obtained maximum density, therefore Will decrease the asphalt stability value. For asphalt penetration the highest density value is at the optimum asphalt level of $5.80 \%$ by $2.11 \%$. 


\subsection{Marshall Flow}

Flow is a state of change in the shape of a mixture due to a load to the limit of collapse. The flow value indicates the degree of flexibility or stiffness of the mixture. High flow values indicate a high degree of flexibility, and vice versa. Increased mixed asphalt levels will also increase the amount of asphalt that envelop aggregate, fatigue time increases in length so that at the time of loading will be better able to follow the change of shape. The results of the research presented in the figure show that the flow value tends to decrease along with the increase of bitumen content.

The flow value of the optimum Retona asphalt level was $5.87 \%$ by $2.11 \mathrm{~mm}$. While the asphalt penetration of $2.23 \mathrm{~mm}$ at the optimum level. In the research, the value of flow tends to decrease with increasing the bitumen content. However, the decrease of the flow value is not too large only ranges from $\pm 0.15 \mathrm{~mm}$ from $0.5 \%$ of the difference of asphalt content, while the penetration asphalt is between $\pm 0.10 \mathrm{~mm}$.

\subsection{Marshall Quotien}

Marshall Quotient is the result between stability and flow. The results of the research shown in the figure can be seen that the MQ value increases with the amount of asphalt content, but will decrease slightly when reaching asphalt level $\pm 6 \%$. Directly the value of Marshall Quotient relates to the value of stability and fatigue.

The results of the research presented in the picture of the relationship between asphalt content with stability, it can be determined the optimum bitumen content of the mixture. The optimum bitumen content is the bitumen content which will yield the best characteristic properties of an asphalt mixture. To find the value of optimum asphalt content, calculation of the regression equation relation of asphalt level with stability.

\section{Conclusion}

1). Characteristics of Marshall of Thin Surfacing Hot Mix Asphalt mixture obtained an optimum Retona rate of $5.87 \%$. The results showed that by using the same gradation obtained optimum asphalt binder content Retona greater than 60/70 penetration bitumen, asphalt That's because it still contains filler Retona $2 \%$, so that the filler in asphalt retona used more than asphalt penetration, nature Filler which tend to absorb the asphalt cause the use of asphalt retona cinderung more than asphalt penetration which its optimum bitumen content is $5,80 \%$.

2). From the Marshall test the properties of retona asphalt cold be concluded that Figures stability of asphalt retona lower than $60 / 70$ penetration bitumen, asphalt stability retona value at the optimum bitumen content $5.87 \%$ by $525,61 \mathrm{Kg}$, while at the optimum level of penetration bitumen gained $5.80 \%$ niali setabilitas $651,16 \mathrm{Kg}$. This illustrates that the retona cinderung asphalt is weaker accepting the load when compared to the asphalt concentration. 3 ). At the optimum bitumen content retona 5.87\% 2.06 density values obtained, the results of research still increased density value at a level of $6 \%, 6.5 \%$ and $7 \%$, this shows the optimum bitumen content retona maximum density is not obtained, so that Will decrease the asphalt stability value. For asphalt penetration the highest density value is at the optimum asphalt level of $5.80 \%$ by $2.11 \%$.

4). The flow value at the optimum retona asphalt level was $5.87 \%$ by $2.11 \mathrm{~mm}$. While the asphalt penetration of $2.23 \mathrm{~mm}$ at the optimum level. In the research, the value of flow that cinderung decreased with increasing the bitumen content. It should increase the level of asphalt, the mixture will be more flexible due to the increasing number of asphalt that 
envelop aggregate. But the decline in flow value is not too large only between $\pm 0.15 \mathrm{~mm}$ of each binder content at $0.5 \%$ difference, while the decrease of penetration bitumen ranges between $\pm 0,10 \mathrm{~mm}$.

\section{References}

1. J.C. Nicholls, I. Carswell and J.T. Williams. Durability of Thin Asphalt Surfacing Systems: Part 1 Initial Findings United Kingdom (2002).

2. T.M. Gilbert, P.A. Olivier and N.E. Gale, Conference on Asphalt Pavements for Southern Africa (2004)

3. D. E. Newcomb, and K. R. Hansen, International Conference on Perpetual Pavements. Columbus, Ohio, (2009)

4. B. Yulianto and A. Setyawan, In IOP Conference Series: Materials Science and Engineering, 176(1), 012034 (2017).

5. M.I. Matar, A. Setyawan, and K.A.Sambowo, Jurnal Teknik Sipil, 2(1). (2016)

6. O.M Kabbash, A. Setyawan, and D. Handayani, Jurnal Teknik Sipil, 2(2). (2016)

7. A. Budiarto, H. R. Purnomo, and A. Setyawan. In App.Mech and Mat, 754, 828-832 (2015)

8. I. N. Iskandar, A Setyawan, and S. J. Legowo. Matriks Teknik Sipil 4(2) (2016).

9. D. Woodward and A. Woodside, The International Journal of Pavement Engineering and Asphalt Technology, 12(2).63-77 (2002) 